\title{
Dissecting the relationship between artificial insemination success and bull semen quality in the arid region of Tiaret (Algeria)
}

\author{
Mohamed Achir, Khaled Taïbi*, Leila Ait Abderrahim, Mohamed Boussaid, Kada Souana, Abdelkader Tadj, Toufik Benaissa, Tayeb Gouchich
}

DOI. 10.21931/RB/2022.07.01.18

${ }^{3}$ Faculty of Life and Natural Sciences, University of Tiaret, 14000, Algeria.

Corresponding author: khaledtaibi@hotmail.com

Abstract: Despite being subject to prior assortment, frozen bull sperms commercialized for artificial insemination may present certain morphological defects. The present study aims (i) to assess the artificial insemination success of the most common cattle breeds in Algeria and (ii) to evaluate the possible effects of commercialized bull's semen quality on this operation. Artificial insemination was assessed through four years of field monitoring by inseminating different cattle breeds of normal fertility. However, semen quality was evaluated using light microscopy by measuring viability, motility, and morphological abnormalities of spermatozoa. Field study revealed a high percentage of normal calving in red and white Holstein breed (44.83 \%) against the high percentage of embryonic mortality (46.43 \%) and calving with a malformation (10.71 \%) in Montbéliarde breed. Semen quality assessment revealed that sperm viability and motility were higher in Holstein breeds than in Montbéliarde. Furthermore, significant differences between semen bulls were found in the proportion of abnormal spermatozoa; a higher rate of sperms with the abnormal head was observed in the black and white Holstein breed (69.3 $\pm 10.98 \%)$. However, the percentage of abnormal sperms with tail defects was higher in the Montbéliarde breed (67.5 $\pm 10.74 \%)$. The lousy quality of the selected semen and/or the poor handling and storage of frozen semen constitute a determinant factor that hinders the success of artificial insemination in the arid region of Tiaret (Algeria).

Key words: Dairy and beef cattle, artificial insemination, sperm abnormalities, calving, embryogenic mortality, Tiaret, Algeria.

\section{Introduction}

Livestock production significantly reinforces the socio-economic lives of people throughout the creation of employment opportunities and deliverance of household incomes, mainly in undeveloped countries. Furthermore, several products and by-products derived from livestock have a significant nutritional and economic value, such as meat and milk, which constitute veritable protein sources for consumers ${ }^{1}$. However, the development of livestock productivity is faced with several constraints, especially in arid and semiarid regions, limiting severely sustainable livestock production.

Indeed, the livestock farming sector has experienced several biotechnological progressions during the last decades with the primary goal of enhancing productivity and improving genetic gain ${ }^{2}$. In this sense, artificial insemination was the most common biotechnology practiced in farm animals, particularly dairy cattle, to improve breeding and obtain genetic advances ${ }^{3}$. The wide use of bovine artificial insemination as efficient reproductive biotechnology is due mainly to the development of cryopreservation methods ensuring spermatozoa viability, from the best breeding bulls, after long periods of storage that can be used to inseminate thousands of cows worldwide ${ }^{4}$. The latest available statistics of the National Center for Artificial Insemination and Genetic Improvement (2017) have reported a success rate of the whole national insemination program ranging from $45 \%$ to $48 \%$ in Algeria.
Several factors are responsible for the success of artificial insemination outcomes and require appropriate attention, such as female physiology, farm management and quality of semen used in the programs 5 . Though selected beforehand, frozen bull spermatozoa commercialized for artificial insemination may present specific morphological abnormalities ${ }^{3}$. Abnormal spermatozoa might reflect troubles in the spermatogenesis process that affect normal spermatozoa of the same ejaculate ${ }^{6,7}$. In general, poor spermatozoa morphology

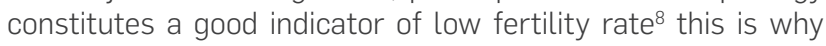
it is essential to analyze spermatozoa morphology to predict fertilizing capacity ${ }^{9}$.

Therefore, the aim of this study is (i) to evaluate the success of artificial insemination program in the arid regions of Tiaret (Algeria), throughout field monitoring carried out in fifteen pilot farms during the period 2016-2019, then (ii) to assess the quality of commercialized bull semen used in reproductive programs in Algeria throughout the estimation of morphological abnormalities of the most common dairy and beef breeds bulls to determine the possible presence of variations between them, regarding the proportion of abnormal spermatozoa.

Citation: Achir M, Taïbi K, Ait Abderrahim L, Boussaid M, Souana K, Tadj A, Benaissa T, Gouchich T. Dissecting the relationship between artificial insemination success and bull semen quality in the arid region of Tiaret (Algeria). Revis Bionatura 2022;7(1). 18. http://dx.doi.org/10.21931/ $\mathrm{RB} / 2022.07 .01 .18$

Received: 10 June 2021 / Accepted: 15 October 2021 / Published: 15 February 2022

Publisher's Note: Bionatura stays neutral with regard to jurisdictional claims in published maps and institutional affiliations. 


\section{Materials and methods}

The scientific committee approved the study for ethical criterion in the department of Natural and Life Sciences, Ibn Khaldoun University of Tiaret (Algeria) (Ref. 05/SCDNLS/2018).

\section{Bull semen samples}

The present study was performed on certified frozen semen straws belonging to selected dairy and beef breeds obtained from the National Center for Artificial Insemination and Genetic Improvement (Algiers, Algeria). Frozen semen samples of breeding bulls were produced in $0.25 \mu \mathrm{l}$ straws where each straw contained approximately 25 million spermatozoa. The semen samples were frozen with the same routine $\mathrm{cr}$ yopreservation technology using the same extender.

Our study involved three bulls selected by the National Center for Artificial Insemination and Genetic Improvement according to their performance representing the three most common breeds in Algeria, namely the bull Jetstream for Montbéliarde breed, Jopic for Red and white Holstein breed and Jukebox for Black and white Holstein breed.

\section{Field monitoring of artificial insemination}

The field monitoring of the artificial insemination success using the selected semen was conducted from 2016-2019 in fifteen dairy farms located in the region of Tiaret. A total of 86 cows known to be of normal fertility were selected for the study encompassing the main frequent dairy breeds in the region, i.e., 29 black and white Holstein, 29 red and white Holstein and 28 Montbéliarde cows.

All the farms subject to this study have the same management model; livestock buildings are similar in design, hygienic conditions and alimentation. Besides, health care was supervised by veterinarians. It should also be noted that cows were inseminated with semen originating from the same batch of tested samples.

\section{Semen quality analysis}

For semen analysis, straws were thawed at $37^{\circ} \mathrm{C}$ for 30 seconds, then they were maintained at the same temperature during the processing. The percentage of spermatozoa motility in each semen sample (around $10 \mu \mathrm{L}$ ) was determined using a phase-contrast microscope supplied with a warm stage adjusted to $37^{\circ} \mathrm{C}$.

After that, bull semen samples were diluted and fixed in pre-warmed $\left(37^{\circ} \mathrm{C}\right)$ formaldehyde-PBS. At that point, a smear from diluted semen was made on a glass slide then was stained by eosin (1.67\%) and nigrosin (10\%) stain according to the protocol established by Moskovtsev and Librach (10). In this sense, at least 200 spermatozoa cells were examined per slide from each bull sample at 400x and 1000x magnification using a phase-contrast microscope (Leica DM2500; Wetzlar, Germany) to assess their viability and morphological abnormalities. The number of spermatozoa cells bearing head, midpiece and tail morphological abnormalities were recorded as previously described by Menon, Barkema ${ }^{11}$.

\section{Data analysis}

Data were subjected to a one-way analysis of variance to determine the effect of breed type on the measured parameters. Comparison between breeds was carried out using the test of Duncan. The significant differences between means and percentages were determined at the $\mathrm{P}<0.05$ level. In all cases, data were examined for normality and homogeneity of variances and identified for any violations of assumptions. The statistical analyses were performed using the computing environment R (R Development Core Team, 2013).

\section{Results}

\section{Field monitoring}

Field monitoring of the artificial insemination operation carried out during 2016-2019 has raised several concerns (Table 1). The percentage of normal calving was comprised between the high value of $44.83 \%$ noticeable for the red and white Holstein breed and low values of $25 \%$ and $27.59 \%$ distinguished respectively in Montbéliarde and black and white Holstein breeds. Furthermore, a higher proportion of embryonic mortality was recorded in the Montbéliarde breed (46.43\%) in comparison to red and white (20.69\%) and black and white Holstein breeds (17.24\%). Besides, it should be noted that a significant proportion of $10.71 \%$ of calving with malformation has been registered in the Montbéliarde breed.

\section{Semen analysis}

Semen analysis has revealed that individual spermatozoa motility was significantly higher in Holstein breeds $(46.37 \pm 11.22 \%$ in red and white and $46.28 \pm 12.94 \%$ in black and white Holstein respectively) in comparison to Montbéliarde $(34.74 \pm 8.46 \%)$. By the same, red and white $(41.48 \pm 5.3 \%)$ and black and white Holstein breeds (41.33 $\pm 17.2 \%)$ have demonstrated high spermatozoa viability when compared with

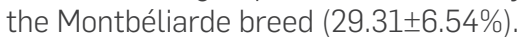

The most frequent spermatozoa morphological abnormalities found in the head, midpiece and tail are shown in Tables 2, Figure 1. The black and white Holstein breed was characterized mainly by spermatozoa head defects, while red and white Holstein and Montbéliarde breeds were characterized mainly by spermatozoa tail defects.Significant differences between breeds were found in the proportion of spermatozoa with abnormal head ( $p$-value $\left.<0.001^{\star \star \star}\right)$; a higher rate was observed in black and white Holstein breed $(69.3 \pm 10.98 \%)$ while it was around $34.54 \pm 18.01 \%$ and $25.28 \pm 8.95 \%$ respectively in red and white Holstein and Montbéliarde breeds. Remarkably, the percentage of spermatozoa with abnormal midpieces was comparable among the examined breeds ( $p$-value $>0.05$ non-significant). However, the percentage of abnormal spermatozoa with tail defects was significantly higher in the Montbéliarde breed $(67.5 \pm 10.74 \%)$ followed by the red and white Holstein breed $(46.15 \pm 17.68 \%)$ while the lowest percentage was recor-

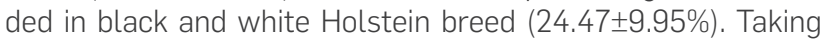

\begin{tabular}{|l|c|c|c|c|}
\hline Breed & $\begin{array}{c}\text { Normal } \\
\text { calving }\end{array}$ & $\begin{array}{c}\text { Embryonic } \\
\text { mortality }\end{array}$ & Gravid & $\begin{array}{c}\text { Calving with } \\
\text { malformation }\end{array}$ \\
\hline Black and white Holstein & $8(27.6 \%)^{\mathrm{a}}$ & $5(17.2 \%)^{\mathrm{a}}$ & $12(41.4 \%)^{\mathrm{c}}$ & $/$ \\
\hline Red and white Holstein & $13(44.8 \%)^{\mathrm{b}}$ & $6(20.7 \%)^{\mathrm{a}}$ & $10(34.5 \%)^{\mathrm{b}}$ & $/$ \\
\hline Montbéliarde & $7(25 \%)^{\mathrm{a}}$ & $13(46.4 \%)^{\mathrm{b}}$ & $5(17.9 \%)^{\mathrm{a}}$ & $3(10.7 \%)$ \\
\hline
\end{tabular}

Table 1. Field monitoring of the cows inseminated artificially by the selected bull semen breeds in the region of Tiaret, Algeria. 


\begin{tabular}{|l|l|l|l|l|l|}
\hline Breed & $\begin{array}{l}\text { Individual } \\
\text { spermatozoa } \\
\text { motility (\%) }\end{array}$ & $\begin{array}{l}\text { Spermatozo } \\
\text { a viability } \\
\mathbf{( \% )}\end{array}$ & $\begin{array}{l}\text { Head defects } \\
\mathbf{( \% )}\end{array}$ & $\begin{array}{l}\text { Midpiece } \\
\text { defects (\%) }\end{array}$ & $\begin{array}{l}\text { Tail defects } \\
\mathbf{( \% )}\end{array}$ \\
\hline $\begin{array}{l}\text { Black and } \\
\text { white Holstein }\end{array}$ & $46.28 \pm 12.94^{\mathrm{b}}$ & $41.33 \pm 17.2^{\mathrm{b}}$ & $69.3 \pm 10.98^{\mathrm{c}}$ & $23.42 \pm 6.59^{\mathrm{a}}$ & $24.47 \pm 9.95^{\mathrm{a}}$ \\
\hline $\begin{array}{l}\text { Red and white } \\
\text { Holstein }\end{array}$ & $46.37 \pm 11.22^{\mathrm{b}}$ & $41.48 \pm 5.3^{\mathrm{b}}$ & $34.54 \pm 18.01^{\mathrm{b}}$ & $25.79 \pm 6.87^{\mathrm{a}}$ & $46.15 \pm 17.68^{\mathrm{b}}$ \\
\hline Montbéliarde & $34.74 \pm 8.46^{\mathrm{a}}$ & $29.31 \pm 6.54^{\mathrm{a}}$ & $25.28 \pm 8.95^{\mathrm{a}}$ & $36.95 \pm 12.76^{\mathrm{b}}$ & $67.5 \pm 10.74^{\mathrm{c}}$ \\
\hline
\end{tabular}

Table 2. Individual spermatozoa motility, spermatozoa viability and morphological abnormalities of the selected bull semen used for artificial insemination programmes in Algeria.

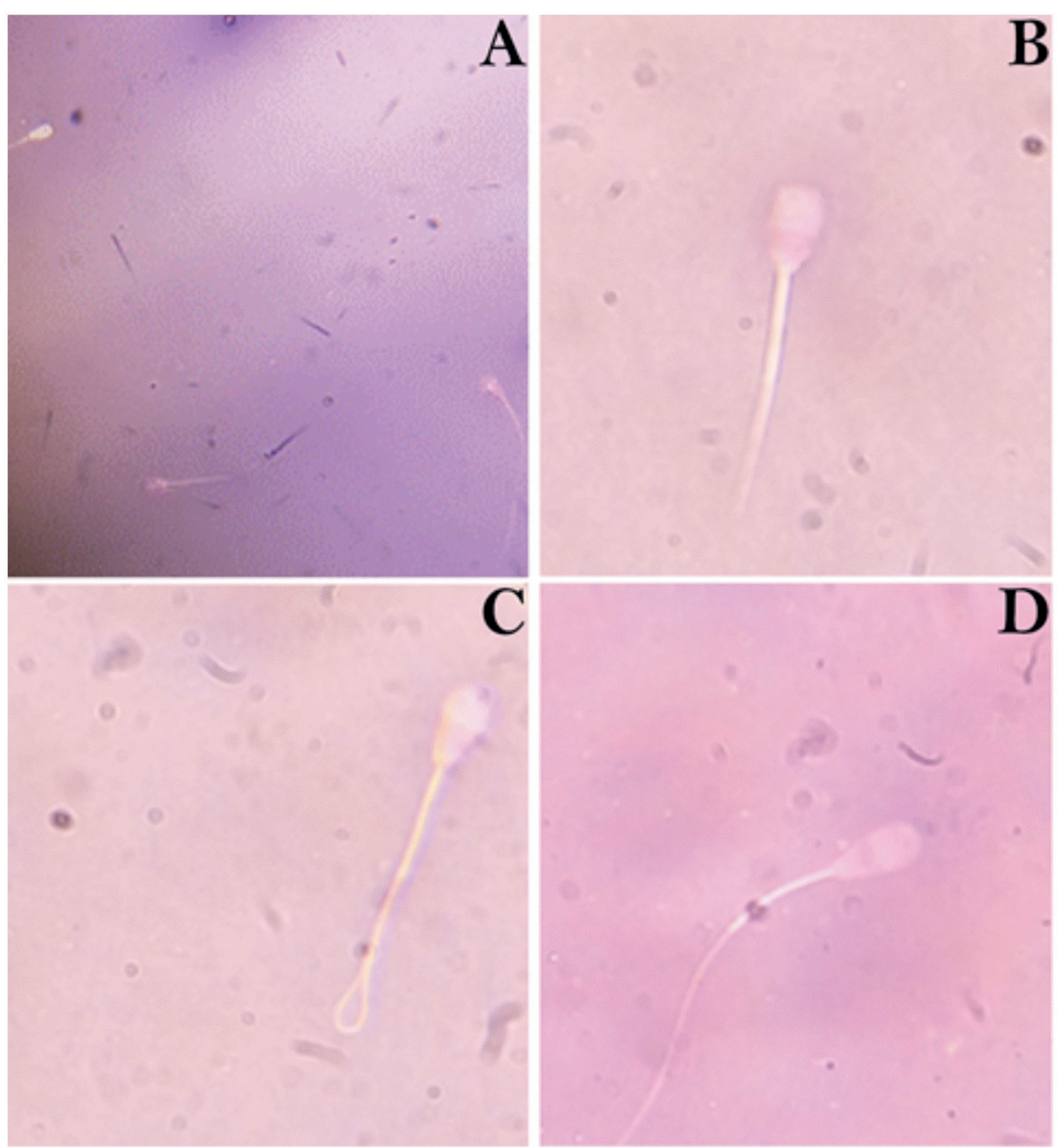

Figure 1. Semen morphology in frozen/thawed bull doses for artificial insemination. A: normal spermatozoa; B: Head defect; C: Tail defect; D: midpiece defect. 
all together, the statistical correlation based on the coefficient of Pearson has demonstrated a significant positive correlation between individual spermatozoa motility and spermatozoa viability $\left(r\right.$-value $\left.=0.61^{* *}\right)$ alongside a significant negative correlation among spermatozoa head defects and spermatozoa tail defects $\left(r\right.$-value $\left.=0.84^{* *}\right)$.

\section{Discussion}

Artificial insemination is widely practiced as reproductive biotechnology to manage a large number of cows reducing animal handling and labor ${ }^{12}$. The present study aims to assess the rate of success of the artificial insemination program on the most common cattle breeds raised in the arid region of Tiaret (Algeria) throughout field monitoring carried out for almost five consecutive years. In addition, the quality of the commercialized bull semen was also evaluated to examine its effects on this operation.

Several factors might determine the success rate of bovine artificial insemination programs, such as female physiology, cattle breed, suckling, size of ovulatory follicle and timing of insemination ${ }^{13}$. The obtained results revealed a high percentage of normal calving in red and white Holstein breeds. However, the percentage of embryonic mortality and/or calving with malformation was higher in the Montbéliarde breed.

It should be noted that embryonic mortality is very difficult to diagnose since it can generally be infectious (less than $30 \%$ ) and non-infectious (more than $70 \%$ ) causes ${ }^{14}$. Uterine contamination by pathogens leads to endometritis and might also induce a direct cytolytic effect on the embryo, systemic effects via septicemias, viremias or toxemias on the dam ${ }^{15}$. Viruses, bacteria, protozoa, and probably mycoplasma pass in the uterus through the hematogenous way or the vagina. However, non-specific pathogens, primarily bacteria, enter the uterus by ascending infection. Furthermore, non-infectious causes of early embryonic death are chromosomal aberrations or external factors, e.g., high ambient temperature, nutritional factors and maternal factors ${ }^{16}$.

The Montbéliarde breed belongs to the group of Pie Rouge breeds (Simmental and Fleckvieh families). In addition to its milk and meat being highly appreciated by consumers, Algerian farmers prefer to raise Montbéliarde cows because of their excellent hardiness and adaptability to local environmental conditions compared to the Holstein breeds ${ }^{17}$.

Semen quality assessment revealed that spermatozoa viability and motility were higher in Holstein breeds than in Montbéliarde. Rodríguez-Martínez ${ }^{18}$ has reported that measured spermatozoa motility in bulls is significantly correlated to fertility even for post-thawed semen.

A higher proportion of spermatozoa with the abnormal head was observed in the black and white Holstein breed, while the percentage of abnormal spermatozoa with tail defects was higher in the Montbéliarde breed. These results clearly illustrate the terrible quality of the selected semen and/or the poor handling and storage of commercial frozen semen, which dramatically reduced the chance of success of artificial insemination programs in Algeria. Hallap, Jaakma ${ }^{19}$ reported a high percentage of spermatozoa with standard head and tail morphology in Estonian Holstein bulls. In general, scrotal circumference, as the most accessible measure of a bull's ability to produce adequate spermatozoa, correlates positively with testicular volume and semen quality ${ }^{20}$ and negatively with the occurrence of spermatozoa defects ${ }^{21}$.

It is known that morphologically abnormal spermatozoa can diminish fertilization rates and embryonic development ${ }^{22}$ The maximum acceptable value for spermatozoa abnormalities percentage ranges between $25 \%$ and $30 \%{ }^{3}$. In general, bull semen is classified as satisfactory if it contains at least $70 \%$ morphologically normal spermatozoa, with less than $20 \%$ of spermatozoa with an abnormal head ${ }^{11}$. Unfortunately, the results indicated that more than two folds significantly exceed these levels for the three tested breeds.

Morphologically abnormal spermatozoa resulting from an abortive apoptotic mechanism or genetic origin are usually characterized by highly damaged DNA ${ }^{23}$. Most abnormalities of the spermatozoa head are closely associated with reduced fertility since the spermatozoa head comprises the genetic material and key effectors of fertilization ${ }^{11}$. Similar observations have been made by Johnson ${ }^{24}$ and Ostermeier, Sargeant ${ }^{25}$ regarding abnormal condensation of chromatin and abnormal nuclear shape from a part and bulls' fertility from another part. Thundathil, Palasz ${ }^{26}$ have demonstrated that spermatozoa with abnormal heads reduce fertilization and embryonic development, consequently leading to cleavage failure. Spermatozoa with abnormal midpiece or tail are either non-motile or have abnormal motility; usually, aberrations of these parts occur as spermatogenesis defects and affect spermatozoa motility ${ }^{11}$.

Besides, the process of freezing and thawing might induce irreversible damages to spermatozoa membranes, resulting in either the occurrence of spermatozoa abnormalities or cell death ${ }^{18}$. John Morris, Acton ${ }^{27}$ has reported that at rapid cooling rates, the cell damage to spermatozoa is a result of an osmotic imbalance encountered during thawing, rather than intracellular ice formation. In addition, Ghirardosi, Fischman ${ }^{3}$ have attributed the high occurrence of abnormal head spermatozoa to the adverse effects of cryopreservation. Furthermore, Bacinoglu, $\operatorname{Taş}^{28}$ demonstrated that morphological abnormalities present in frozen and thawed semen were significantly lower in high-fertile bulls.

According to our records, this study represents the first analysis of morphological spermatozoa abnormalities in doses of bovine semen promoted for artificial insemination currently marketed in Algeria.

\section{Conclusions}

The present study evaluated the artificial insemination success of the most common cattle breeds raised in Algeria through four years of field monitoring and assessed the quality of commercialized bull's semen used in this operation.

Overall, the present study results have demonstrated a high percentage of normal calving in red and white Holstein breeds. However, embryonic mortality and calving with malformation were higher in the Montbéliarde breed. Besides, assessment of semen quality revealed high spermatozoa viability and motility in Holstein breeds compared to Montbéliarde. In addition, the rate of spermatozoa with the abnormal head was higher in the black and white Holstein breed, while the percentage of abnormal spermatozoa with tail defects was higher in the Montbéliarde breed.

In general, it appears that the bad quality of the selected semen and/or the poor handling and storage of frozen semen constitute a determinant factor that hinders the success of artificial insemination in Algeria. Therefore, spermatozoa morphology assessments are highly recommended before processing and freezing and even in post-thawed commercial doses. Further studies regarding the modalities of distribution 
and processing are also recommended, so that in the future the use of bull semen with high percentages of spermatozoa abnormalities might be avoided.

\section{Bibliographic references}

1. Mudzengi CP, Dahwa E, Kapembeza CS. Livestock Feeds and Feeding in Semiarid Areas of Southern Africa. 2020. In: Livestock Health and Farming [Internet]. Available from: https://www. intechopen.com/books/livestock-health-and-farming/livestockfeeds-and-feeding-in-semi-arid-areas-of-southern-africa.

2. Göncü S, Güngör $C$. The Innovative Techniques in Animal Husbandry. 2018. In: Animal Husbandry and Nutrition [Internet]. [422].

3. Ghirardosi MS, Fischman ML, Jorge AE, Chan D, Cisale H. Relationship between morphological abnormalities in commercial bull frozen semen doses and conception rate. 2018;50(3):e12884

4. Ugur MR, Saber Abdelrahman A, Evans HC, Gilmore AA, Hitit M, Arifiantini RI, et al. Advances in Cryopreservation of Bull Sperm. Front Vet Sci. 2019;6:268-.

5. Jemal H, Lemma A. Review on Major Factors Affecting the Successful Conception Rates on Biotechnological Application (AI) in Cattle. The Journal of medical research. 2015;15(3):29-37.

6. Sharpe RM. Environmental/lifestyle effects on spermatogenesis. Philos Trans R Soc Lond B Biol Sci. 2010;365(1546):1697-712.

7. Massart A, Lissens W, Tournaye H, Stouffs K. Genetic causes of spermatogenic failure. Asian J Androl. 2012;14(1):40-8.

8. Attia S, Katila T, Andersson M. The Effect of Sperm Morphology and Sire Fertility on Calving Rate of Finnish Ayrshire Al Bulls. Reproduction in domestic animals = Zuchthygiene. 2016;51(1):54-8.

9. Saacke RG. Sperm morphology: Its relevance to compensable and uncompensable traits in semen. Theriogenology. 2008;70(3):4738.

10. Moskovtsev SI, Librach CL. Methods of sperm vitality assessment. Methods in molecular biology (Clifton, NJ). 2013:927:13-9

11. Menon AG, Barkema HW, Wilde R, Kastelic JP, Thundathil JC. Associations between sperm abnormalities, breed, age, and scrotal circumference in beef bulls. Can J Vet Res. 2011;75(4):241-7.

12. Oliveira LZ, de Arruda RP, de Andrade AFC, Celeghini ECC, dos Santos RM, Beletti ME, et al. Assessment of field fertility and several in vitro sperm characteristics following the use of different Angus sires in a timed-Al program with suckled Nelore cows. Livestock Science. 2012;146(1):38-46.

13. Meneghetti M, Filho OGS, Peres RFG, Lamb GC, Vasconcelos JLM. Fixed-time artificial insemination with estradiol and progesterone for Bos indicus cows I: Basis for development of protocols. Theriogenology. 2009;72(2):179-89.

14. Vanroose G, de Kruif A, Van Soom A. Embryonic mortality and embryo-pathogen interactions. Anim Reprod Sci. 2000;6061:131-43.
15. Blackwell TE, Werdin RE, Eisenmenger MC, FitzSimmons MA. Goitrogenic effects in offspring of swine fed sulfadimethoxine and ormetoprim in late gestation. Journal of the American Veterinary Medical Association. 1989;194(4):519-23.

16. Shah BR. Factors Leading to Early Embryonic Death Nepalese Veterinary Journal. 2019;36:118-25.

17. Allouche L, Madani T, Mechmeche M, Bouchemal A. Reproductive performance of Montbeliard cows reared under subtropical environment: effects of heat stress and acclimatization duration. . Livestock Research for Rural Development. 2018;30.

18. Rodríguez-Martínez H. Laboratory semen assessment and prediction of fertility: still utopia? Reproduction in domestic animals = Zuchthygiene. 2003;38(4):312-8.

19. Hallap T, Jaakma U, Rodriguez-Martinez $\mathrm{H}$. Changes in semen quality in Estonian Holstein Al bulls at 3, 5 and 7 years of age. Reproduction in domestic animals = Zuchthygiene. 2006;41(3):2148.

20.Benia AR, Taïbi K, Ait-Amrane A, Belhamiti T, Hammoudi SM, Kaidi R. Study of seasonal sexual activity variations in Algerian rams: Sexual behaviour, testosterone concentration control and environmental factors. African Journal of Biotechnology. 2013;12(41):6042-8.

21. Kastelic JP, Cook RB, Pierson RA, Coulter GH. Relationships among scrotal and testicular characteristics, sperm production, and seminal quality in 129 beef bulls. Can $J$ Vet Res. 2001;65(2):111-5.

22. Walters AH, Eyestone WE, Saacke RG, Pearson RE, Gwazdauskas FC. Bovine embryo development after IVF with spermatozoa having abnormal morphology. Theriogenology. 2005;63(7):1925-37.

23. Enciso M, Cisale H, Johnston SD, Sarasa J, Fernández JL, Gosálvez J. Major morphological sperm abnormalities in the bull are related to sperm DNA damage. Theriogenology. 2011;76(1):23-32.

24. Johnson WH. The significance to bull fertility of morphologically abnormal sperm. The Veterinary clinics of North America Food animal practice. 1997;13(2):255-70.

25. Ostermeier GC, Sargeant GA, Yandell BS, Evenson DP, Parrish JJ. Relationship of bull fertility to sperm nuclear shape. Journal of andrology. 2001;22(4):595-603.

26. Thundathil J, Palasz AT, Mapletoft RJ, Barth AD. An investigation of the fertilizing characteristics of pyriform-shaped bovine spermatozoa. Anim Reprod Sci. 1999;57(1-2):35-50.

27. John Morris G, Acton E, Murray BJ, Fonseca F. Freezing injury: the special case of the sperm cell. Cryobiology. 2012;64(2):71-80.

28. Bacinoglu S, Taş M, Cirit U, Ozdaş OB, Ak K. The potential fertility estimation capacity of the hypoosmotic swelling test, the thermal stress test and a modified cervical mucus penetration test in the bovine. Anim Reprod Sci. 2008;104(1):38-46. 